\title{
Letramento ficcional e letramento literário: reflexões sobre usos de textos ficcionais a partir dos estudos de letramento
}

\author{
Mirian Hisae Yaegashi Zappone \\ Stéfanny Barranco do Nascimento**
}

Existem diferentes formas de se usar a escrita e, evidentemente, a escrita e a leitura de textos literários é uma delas. Assim, por abarcar, indubitavelmente, usos de textos literários tanto na esfera da produção quanto da recepção de textos, podese dizer que os estudos literários estão implicados com questões de letramento. Entretanto, são recentes e rarefeitos os estudos que relacionam a leitura de textos literários a letramento. Em texto de natureza normativa, a expressão "letramento literário" aparece, pela primeira vez, em 2006, nas Orientações Curriculares Nacionais para o Ensino Médio - Linguagens, Códigos e suas Tecnologias. Antes desse documento, pesquisadores ligados ao Centro de Alfabetização, Leitura e Escrita (CEALE), da Faculdade de Educação da Universidade Federal de Minas Gerais publicam o livro "Literatura e letramento: espaços, suportes e interfaces", em 2003, no qual o termo "letramento literário" é utilizado por alguns autores, como se nota em "Letramento literário e o livro didático de língua portuguesa: os amores difíceis", de Egon de Oliveira Rangel ou "Letramento literário: não ao texto, sim ao livro", de Regina Zilberman. Em 2006, Rildo Cosson é responsável pela publicação de vários artigos no qual faz uso do sintagma, sendo, notadamente, mais conhecido o livro "Letramento literário: teoria e prática", também de 2006.

Muito embora utilizem o termo letramento, uma característica desses textos é que nenhum deles, apesar de apropriarem-se de um conceito discutido a partir do final dos anos 1980, anos 1990 e em todo o início do século XXI, não se valem das teorias de letramento propriamente ditas para a proposição do conceito de "letramento literário". Assim, aspectos teóricos importantes dos estudos de letramento deixam de ser levantados em tais textos, uma vez que eles desconsideram o percurso investigativo anteriormente desenvolvido no âmbito dos estudos linguísti-

\footnotetext{
Professora adjunta da Universidade Estadual de Maringá, Brasil. E-mail: mhyzappone@uem.br.

* Professora de Língua Portuguesa. Graduada em Letras pela Universidade Estadual de Maringá, Brasil. E-mail: stefannynascimento@hotmail.com .
} 
cos, e que, cremos, pode oferecer inúmeros subsídios teóricos para a compreensão das práticas de usos de textos literários e mesmo a forma como a literatura é escolarizada. Tendo em vista esse contexto, é objetivo desse artigo realizar uma apropriação do conceito de letramento a partir dos Novos Estudos de Letramento (STREET, 1984, 2014), a fim de relacioná-lo com as questões da leitura do texto literário e com a questão de seu ensino na escola, para o que, necessariamente, abordaremos o conceito de letramento aqui adotado e outros aspectos teóricos a ele relacionados, como os modelos de letramento.

\section{Sobre os conceitos de letramento}

Segundo Soares (1998), o conceito de letramento foi utilizado pela primeira vez no Brasil por Mary Kato no texto "No mundo da escrita: uma perspectiva psicolinguística", de 1986. Em 1988, Leda V. Tfouni utiliza o termo no livro Adultos alfabetizados: o avesso do avesso, ampliando sua divulgação e sua utilização nos meios acadêmicos. Em 1995, a coletânea de artigos organizada por Angela B. Kleiman, Os significados do letramento: uma nova perspectiva sobre a prática social da escrita, evidencia a ampliação dos estudos de letramento. Com seus artigos, publicados nos anos finais de 1990 e, efetivamente, com o livro Letramento: um tema em três gêneros, de 1998, Magda Soares foi, em grande parte, responsável pela incorporação do termo nos discursos acadêmicos e nas falas de profissionais da área da educação e das letras.

A abordagem do mesmo tema por diferentes pesquisadoras evidencia não só a difusão do termo no Brasil, mas também a pluralidade de perspectivas sob a qual ele é tratado. Para Leda Verdiani Tfouni, o conceito de letramento está relacionado à sua distinção em relação à alfabetização. Para ela, "enquanto a alfabetização ocupa-se da aquisição da escrita por um indivíduo, o letramento focaliza os aspectos sócio-históricos da aquisição de um sistema escrito por uma sociedade" (TFounI, 1995, p. 20). Assim, a autora focaliza no conceito de letramento a questão das consequências que as "práticas letradas" podem causar em grupos de indivíduos, ou seja, destaca o âmbito social dos usos da escrita e as mudanças sociais/individuais por eles patrocinados nos grupos que dela se apropriam:

A alfabetização pertence, assim, ao âmbito do individual. O letramento, por sua vez, focaliza os aspectos sócio-históricos da aquisição da escrita. Entre outros casos, procura estudar e descrever o que ocorre nas sociedades quando adotam um sistema de escritura de maneira restrita ou generalizada; procura ainda saber quais práticas psicossociais substituem as práticas "letradas" em sociedades ágrafas (TFOUNI, 1988, p. 9).

Magda Soares, ao definir letramento, considera as consequências geradas nos indivíduos pelos usos que fazem da escrita, de forma a considerar letramento o "estado ou condição daquele que é literate [letrado], daquele que não só sabe ler e escrever, mas também faz uso competente e frequente da leitura e da escrita" 
(SOARES, 1998, p. 36). Assim, a pesquisadora focaliza os "impactos" da escrita, as consequências que os usos da escrita podem trazer na vida dos grupos ou das pessoas. Implícita nesse conceito está a ideia de que a escrita "traz consequências sociais, culturais, políticas econômicas, cognitivas, linguísticas, quer para o grupo em que seja introduzida, quer para o indivíduo que aprenda a usá-la" (SOARES, 1998, p. 17).

Para Ângela Kleiman, o conceito de letramento está diretamente associado à noção de práticas, ou seja, a um fazer, às ações produzidas pelos indivíduos em situações de uso da escrita. Para a autora, letramento está associado aos modos como os indivíduos utilizam a escrita, considerando fundamentais os contextos e objetivos nos quais tais práticas são realizadas: "Podemos definir hoje o letramento como um conjunto de práticas sociais que usam a escrita, enquanto sistema simbólico e enquanto tecnologia, em contextos específicos, para objetivos específicos" (Kleiman, 1995, p. 19). Nas três autoras e em outros que se seguem a elas, o conceito de letramento ora se associa à noção de práticas sociais, ora se vincula à noção de "condição". Os pesquisadores associados aos Novos Estudos de Letramento, particularmente Brian. Street e Mary Hamilton, aos quais se alinham, no Brasil, Angela Kleiman, Roxane Rojo e outros, concebem letramento como ação de uso da escrita, abordagem na qual também se fundamenta esse texto e sob a qual a discussão sobre letramento será proposta.

Diferentes áreas do conhecimento - história, antropologia, psicologia, pedagogia, linguística entre outras -, a partir de seus pressupostos teóricos e/ou metodológicos, buscam compreender os inúmeros usos da escrita, bem como sua relação com a oralidade e seus usos em variados contextos sociais e a(s) consequência(s) desses usos, tanto coletivamente quanto individualmente. Houve, a partir das últimas décadas, a construção e consolidação de pesquisas sobre as culturas escritas e sobre como a escrita se configura dentro de determinados contextos sociais. Pesquisadores como Brian Street, James Paul Gee, David Barton, Mary Hamilton, no exterior, e no Brasil, Magda Soares, Angela Kleiman, Leda V. Tfouni, Neiva Jung entre outros, com abordagem por vezes etnográfica, e evidenciando a base social do letramento, têm apontado para as práticas reais, ou seja, para os usos de letramento e ratificado como essas práticas influenciam o cotidiano e a visibilidade dos indivíduos dentro de uma sociedade grafocêntrica. Muitas dessas pesquisas questionam o modelo dominante de letramento em detrimento às outras formas de apropriação e usos da leitura e da escrita, e enfatizam que, antes de promover certos programas de intervenções em alfabetização, é necessário que se compreendam as práticas de letramento que são desenvolvidas diariamente em grupos e comunidades específicos que são alvo das pesquisas realizadas (STREET, 1984), evidenciando que os estudos de letramento se ocupam dos usos empíricos da escrita sem distinção dos espaços nos quais eles podem ocorrer.

Ao observar algumas restrições em teorias sobre o letramento, bem como a consequência de experimentos antropológicos, Brian Street propôs um conjunto al- 
ternativo de conceitos teóricos juntamente com outros pesquisadores (GEE, 1990; Barton, Hamilton e Ivanic, 20oo; Street, 1999), que passou a ser denominado New Literacy Studies/NSL (Street, 1999). A partir dos Novos Estudos do Letramento, a compreensão dos processos de leitura e escrita expande-se, ao relacionarse os usos da escrita e da leitura às transformações que vieram com a globalização, com a tecnologia e com a comunicação. Para Street (2003a, p. 78), a concepção de letramento simboliza "um meio de focalizar as práticas sociais e concepções do ler e escrever" como, por exemplo, fazer compras, participar de uma cerimônia religiosa, assistir à televisão etc. Por essas práticas serem realizadas em contextos específicos para objetivos específicos, é evidente que o letramento não está restrito ao âmbito escolar, embora esse seja um lugar privilegiado no qual ele acontece. O letramento abarca, portanto, os usos e práticas sociais de linguagem que envolvem a escrita, sejam eles valorizados ou não, locais ou globais, recobrindo contextos sociais bastante diversos, tais como família, igreja, trabalho, mídias, escola e outros, numa perspectiva sociológica, antropológica e sociocultural. Há, então, nos estudos de letramento, a tentativa de compreender a leitura e a escrita não apenas no âmbito linguístico, mas também histórico, antropológico, cultural, levando em consideração os diversos locais/situações em que os sujeitos interagem por meio da escrita e, ainda, as relações de poder implicadas nesses usos. Vivenciamos práticas sociais diferentes nas quais diversas ideologias e relações de poder atuam fortemente, principalmente se levarmos em consideração as especificidades das culturas locais, as questões de identidade, das relações (nem sempre igualitárias e pacíficas) entre grupos sociais distintos, aspectos todos que acabam por configurar diferentes usos da escrita, ou "diferentes letramentos".

Os estudos que compreendem letramento como prática social de uso da escrita (Kleiman 1995; Barton, Hamilton e IVAnic, 2004; Street, 1984; 2014) focalizam a natureza social da leitura e da escrita e o caráter múltiplo das práticas letradas, valendo-se de perspectivas transculturais, ou seja, leitura e escrita são permeadas por práticas sociais e, por essa razão, não se dissociam do contexto social, econômico e cultural nos quais ocorrem. Street (2014, p. 13) elucida, a partir de pesquisas antropológicas, que existem múltiplas formas de letramento realizadas em contextos reais; segundo ele, "nessa perspectiva, a relação entre língua escrita e língua oral difere segundo o contexto [...]. Para o autor, as condições sociais e materiais afetam (se é que não determinam) a significação de uma dada forma de comunicação" (STREET, 2014, p. 17).

A partir de um estudo de caso em um vilarejo no Irã, em 1970, Street (2003b, p. 3) observou a existência de outros letramentos que não faziam (fazem) parte da "cultura letrada". Esses letramentos eram vistos pelas vozes dominantes como um letramento inferior, os habitantes eram vistos como "atrasados" e "iletrados". No entanto, ao observar com mais cautela, "o que parecia era que não apenas existia muito letramento acontecendo por ali, mas também existiam 'práticas' bastante diferentes associadas a ele" (STREET, 2003b, p. 3). Nesse sentido, é importante destacar que existem muitos modos de uso da leitura e da escrita que não são visi- 
bilizados, mas que acontecem cotidianamente, ainda que de forma velada e, na maioria das vezes, são vistos como inferiores ao modelo dominante de letramento que é o escolar. A leitura, por exemplo, de textos ficcionais não canônicos (best sellers, romances policiais, séries românticas etc.), realizada por adolescentes fora do contexto escolar, é marginalizada, evidenciando que, também, no caso da leitura de textos ficcionais, há várias práticas que sequer são conhecidas, uma vez que são julgadas inadequadas e até prejudiciais aos leitores quando comparadas com as leituras escolares e de textos da tradição literária. Nota-se, portanto, que os estudos de letramento focalizam os reais usos da escrita, sem distingui-los valorativamente e sem hierarquizar os tipos de escrita com os quais os indivíduos se relacionam em seu cotidiano. Segundo a perspectiva teórica defendida neste artigo, letramento refere-se a todos os usos sociais da escrita, independentemente de sua valoração social ou cultural, uma vez que os estudos de letramento pretendem dar visibilidade a tais usos, pois constituem usos concretos e efetivos da escrita. Nesse sentido, os modelos de letramento propostos por Brian Street se mostram bastante profícuos para a compreensão dos modos de funcionamento desses diferentes letramentos.

\section{Modelos de letramento, escola e ensino de literatura}

A partir das observações feitas no Irã, Street (1984) desenvolveu um estudo em que conceitua dois modelos de letramento: o autônomo e o ideológico. O primeiro funciona com base na suposição de que, em si mesmo, o letramento, de forma autônoma, terá efeitos sobre outras práticas sociais e cognitivas. Entretanto, tal modelo disfarça as suposições culturais e ideológicas sobre as quais se baseia, enquanto o modelo ideológico oferece uma visão com maior sensibilidade cultural às práticas de letramento, na medida em que elas variam de um contexto para outro. Assim, o modelo autônomo de letramento acaba se revelando um padrão reducionista, concebendo a escrita como um produto completo em si mesmo, desvinculada de um contexto. Kleiman (1995) esclarece que o modo autônomo de letramento é comumente praticado na escola; isso porque o processo de interpretação estaria determinado pelo funcionamento lógico interno ao texto escrito, não dependendo das (nem refletindo, portanto) reformulações estratégicas que caracterizam a oralidade (KLEIMAN, 1995, p. 22). A partir de sua teoria sobre o modelo autônomo, que foi reafirmada no livro Literacy and Development - Ethnographic Perspectives, Brian Street elucida que o modelo autônomo de letramento:

funciona a partir do pressuposto de que o letramento em si mesmo - de forma autônoma - terá efeitos sobre outras práticas sociais e cognitivas. O modelo, no entanto, disfarça os pressupostos culturais e ideológicas que lhe estão subjacentes e que podem, então, ser apresentados como se eles fossem neutros e universais (STREET, 2001, p. 7).

O letramento autônomo abarca um modelo de letramento que desconsidera o contexto social, pois está focado no ensino de aquisição de habilidades e baseado 
em noções de neutralidade e universalidade do conhecimento a ser transmitido. Nesse modelo, baseado em uma visão de padrão, o letramento, por si mesmo, ou seja, autonomamente, é capaz de produzir efeitos sobre práticas cognitivas e sociais, sendo dispensável a consideração das condições sociais, culturais e econômicas inerentes à vida social.

Mesmo em meio aos usos de diversos tipos de letramento praticados pelos indivíduos, o letramento associado à escola (modelo autônomo) é definidor, tanto para firmar um padrão quanto para marginalizar outros usos da leitura e da escrita. Tanto na escola quanto na vida social, há o que Street (2014) chama de pedagogização do letramento, ou seja, há uma objetificação da língua, onde as vozes do letramento dominante ecoam para além dos muros da escola. O autor evidencia essa objetificação de modo a entender como os discursos do letramento autônomo ecoam na sociedade, bem como têm relação direta com a pedagogização do letramento. Segundo ele, a construção e a interiorização do modelo autônomo alcançam sucesso porque há um distanciamento entre a língua e os sujeitos, ou seja, a língua escrita é tratada como algo divino e, consequentemente, há certo afastamento dos usuários, pois "os processos sociais de leitura e escrita são referenciados e lexicalizados dentro de uma voz pedagógica como se fossem competências independentes e neutras" (STREET, 2014, p. 131). Logo, vista assim, a língua escrita estaria destituída de significação ideológica e não estaria sujeita às relações de poder que permeiam a esfera social na qual os indivíduos se situam. Além disso, é evidente o status que se confere à escrita em comparação à oralidade, como se a primeira fosse "intrinsecamente superior e, portanto, como se aqueles que a adquirissem também se tornassem superiores" (STREET, 2014, p. 130). Além do exposto, Street (2014) observa que, dentro de sala de aula, a língua é vista como se fosse algo externo tanto para os alunos quanto para os próprios professores, como se ela tivesse qualidades autônomas, não sociais. O autor descreve que a "rotulação do espaço [escolar]" e dos "procedimentos [escolares]" contribuem para a construção e interiorização da voz pedagogizante na escola. Para ele, a institucionalização de um modelo de letramento acontece não apenas pelos usos específicos que se faz dele dentro do ambiente escolar, mas ainda pelo próprio espaço físico, "que é separado do espaço 'cotidiano' para fins de ensino e aprendizagem" (STREET, 2014, p. 130). Vale ressaltar que, se ambientes específicos exigem letramentos específicos, é natural que o letramento escolar adquira esta configuração. O problema está em apagar os outros letramentos advindos do meio social em que os indivíduos interagem e estabelecer um modelo como superior aos outros. A superioridade do letramento escolar é tamanha que, fora da escola, a voz pedagogizante do letramento ecoa e é interiorizado pela sociedade.

A influência do modelo autônomo de letramento sobre o modo como a sociedade trata as práticas de letramento fica evidente até mesmo nas normativas governamentais para o ensino básico, ou seja, tal concepção de letramento permeia as políticas públicas de ensino. Exemplo a ser observado são as Orientações Cur- 
riculares Nacionais do Ensino Médio (OCNEM), ${ }^{1}$ de 2006, documento que apresenta complementações aos Parâmetros Curriculares Nacionais para o Ensino Médio (PCNEM), publicados em 1999. Ao se analisarem as propostas de leitura de textos literários, observam-se nelas não apenas a hierarquização de tipos de textos, mas também a adoção de um modo de leitura proposto para os estudantes que se alinha, claramente, a uma leitura que tem como ponto de partida as práticas da cultura letrada.

Apoiando-se enfaticamente no Art. 35, inciso III da Lei de Diretrizes e Bases da Educação Nacional (LDBEN) no. 9.394/96, que preconiza que um dos objetivos do ensino médio é o "aprimoramento do educando como pessoa humana, incluindo a formação ética e o desenvolvimento da autonomia intelectual e do pensamento crítico", o texto das OCNEM tem como meta construir uma perspectiva do ensino de literatura pautada em uma tradição humanista que entende a literatura como arte que pode levar à humanização dos sujeitos. Neste sentido, o documento opõese ao conceito dos usos sociais e da valorização da cultura dos estudantes presentes nos PCNEM, e propõe que os textos literários a serem estudados sejam apenas os textos canônicos que se opõem, diametralmente, aos textos da cultura de massa:

Ao se tratar das orientações curriculares para o ensino da literatura, consideram-se, portanto, em primeiro plano, as criações poéticas, dramáticas e ficcionais da cultura letrada. Tal primazia visa a garantir a democratização de uma esfera de produção cultural pouco ou menos acessível aos leitores, sobretudo da escola pública, fora do ambiente escolar (BRASIL, 2006, p. 55-56, grifo nosso).

[...] sem dúvida, muitos deles [textos da cultura popular] têm importância das mais acentuadas, seja por transgredir, por denunciar, enfim, por serem significativos dentro de determinado contexto, mas isso ainda é insuficiente se eles não tiverem suporte em si mesmos, ou seja, se não revelarem qualidade estética. [...] Qualquer texto escrito, seja ele popular ou erudito, seja expressão de grupos majoritários ou de minorias, contenha denúncias ou reafirme o status quo, deve passar pelo mesmo crivo que se utiliza para os escritos canônicos (BRASIL, 2006, p. 55-56, grifo nosso).

Utilizar o mesmo parâmetro de apreciação artística para produções culturais que são histórica, estilística e semioticamente diferentes parece não ser uma forma muito clara de estabelecer um programa de literatura para a escola. Até mesmo porque, dentro da própria historiografia e crítica literárias, não há consenso sobre quais sejam os aspectos que definem a artisticidade dos textos. Nesse

Os documentos aqui analisados restringem-se ao nível secundário de escolarização, particularmente, ao ensino médio, uma vez que nossos estudos sobre letramento e literatura se concentram nesse nível de ensino. 
sentido, embora não aponte os caminhos para a definição do que é canônico, o documento enfatiza que a escola não é lugar para o estudo de textos da cultura de massa (o rap, a letra de música, o cordel, a HQ). O pressuposto subjacente a este posicionamento parece ser aquele já criticado por De Certeau (1994) de que há clivagens culturais que alinham grupos sociais economicamente desfavorecidos com produções culturais de massa e grupos sociais favorecidos com a cultura elevada. Nesse sentido, a função da escola seria a de patrocinar a "elevação" cultural dos estudantes quando, nas propostas dos PCNEM, o que se pretendia era exatamente compreender como diferentes manifestações culturais funcionam. Assim, um dos problemas das OCNEM consiste em não problematizar a questão do valor estético, evidenciando seu caráter histórico e social enquanto construção pautada em valores dominantes.

O documento se constitui, praticamente, em um diálogo com os PCNEM nos quais se criticam os problemas deste último ao qual são sugeridas outras posturas. Um dos aspectos criticados é a ênfase dos PCNEM à fruição estética. Para os autores das OCNEM, o conceito de fruição presente naquele documento confunde-se com "diversão". A essa acepção, propõem um conceito de fruição atrelado à teoria literária, segundo a qual fruir refere-se à apropriação que o leitor faz do texto literário, concomitante à sua participação na construção do texto, ou seja, o leitor precisa colocar-se como o leitor intratextual imaginado pelo autor a fim de realizar uma leitura adequada do texto. Nesse sentido, essa noção de fruição se aproxima dos pressupostos da Estética da Recepção, na qual o leitor não é um leitor em formação, mas um leitor ideal. Logo, verifica-se que o conceito de leitura pressuposto nas OCNEM é bastante especializado para um nível de escolaridade que ainda é básico.

Outro aspecto enfatizado nas Orientações Curriculares e que evidencia seu alinhamento ao modelo autônomo de letramento diz respeito ao modo de abordagem dos textos, ou seja, ao modo de leitura proposto no documento. Seus autores criticam os PCNEM por proporem uma abordagem que emoldura o texto em seu tempo de produção, compreendendo sua inserção estética particular. Creem que tal inserção leva a escola a uma prática considerada por eles inadequada: "estudar a história da literatura com seus representantes mais ilustres, e identificar as características da escola literária" (BRAsIL, 2006, p. 58). Ora, para que possa ler literariamente um texto, é preciso, como propõe Hansen (2005), que o leitor compreenda os artifícios de ficção nele utilizados, o que pressupõe levar em conta que existe um intervalo temporal entre leitor (real) e texto, de modo que as convenções da escrita presentes no texto precisam ser indicadas, estudadas pelo leitor a fim de que ele possa reconstituir o passado do texto. Nesse sentido, o trabalho do professor se torna fundamental para que o aluno acesse os elementos que reconstituem este passado. Para Hansen (2005), o conhecimento dos gêneros e dos estilos de construção estética dos diversos períodos são elementos que permitem ao leitor essa compreensão do passado do texto e permitem que se efetive a leitura literária, ainda que essa seja, sempre, incompleta e parcial: 
Para que uma leitura se especifique como leitura literária, é consensual que o leitor deva ser capaz de ocupar a posição semiótica do destinatário do texto, refazendo os processos autorais de invenção que produzem o efeito de fingimento. Idealmente, o leitor deve coincidir com o destinatário para receber a informação de modo adequado. Essa coincidência é prescrita pelos modelos dos gêneros e pelos estilos que funcionam como reguladores sociais da recepção, compondo destinatários específicos dotados de competências diversificadas: mas a coincidência é apenas teórica, quando observamos o intervalo temporal e semântico existente entre destinatário e leitor. Assim, a leitura literária é uma poética parcial ou uma produção assimétrica de sentido (HANSEN, 2005, p. 19-20).

Como se nota, sem o conhecimento dos estilos de escrita particulares de cada época, das estruturas e marcas constitutivas dos diversos gêneros literários e mesmo sem uma contextualização adequada de obras e autores (aspectos que são criticados no modo de abordagem proposto pelos PCNEM), a leitura literária, aquela que pode levar à fruição (entendida como ato de se sentir coautor do texto), não tem como se concretizar. Observa-se, portanto, que, embora proponha uma "leitura literária", as OCNEM criticam os aspectos dessa leitura que parecem bastante coerentes na proposta dos PCNEM. O caminho por elas apontado para que se alcance tal leitura é explicitado a partir do "letramento literário" - conceito que não é discutido no documento - entendido apenas como o contato direto do aluno com o texto. Com relação a esse aspecto, pode-se perceber um alinhamento muito direto ao modelo autônomo de letramento, uma vez que, ao supor que a compreensão do texto seja possível apenas pelo contato direto com o texto, postula uma crença na autonomia do texto, como se ele pudesse significar por si só, por sua construção linguística e artística. Para os elaboradores do documento, o problema da leitura de textos literários na escola está na escolha dos textos e também no fato de os estudantes não os lerem, efetivamente. Para os produtores das OCNEM, o contato efetivo com texto, por si só, levaria ao estranhamento e à fruição estética, como se a simples decodificação do texto pudesse promover uma completa compreensão da literatura e fazer com que o estudante se colocasse como o destinatário inicial imaginado pelo autor. Tal posicionamento parece ignorar, totalmente, o fato de que a leitura literária, como se mostrou anteriormente, é uma prática altamente especializada que requer inúmeras mediações, sobretudo quando se trata de estudantes em fase de formação enquanto leitores. O conceito de "letramento literário" presente no documento deixa bem clara tal postura e seu alinhamento ao modelo autônomo de letramento:

Por isso, faz-se necessário e urgente o letramento literário: empreender esforços no sentido de dotar o educando da capacidade de se apropriar da literatura, tendo dela a experiência literária. Estamos entendendo por experiência literária o contato efetivo com o texto. Só assim será possível experimentar a sensação de estranhamento que a elaboração peculiar do texto literário, pelo uso incomum da linguagem, consegue produzir no lei- 
tor, o qual, por sua vez, estimulado, contribui com sua própria visão de mundo para a fruição estética (BRASIL, 2006, p. 55).

A proposta das OCNEM, ao negar o pressuposto bakhitiniano dos usos sociais da linguagem e ao creditar um valor estético diferenciado e uma função humanista para a literatura, alinha-se a uma abordagem que vê no ensino de literatura o poder de transformar os alunos em indivíduos críticos (no sentido ideológico), cuja sensibilidade seria aprimorada pelo contato com a arte legítima (a literatura valorizada pela cultura letrada). É o que se nota quando, ao referir-se às funções da literatura na escola, as OCNEM fazem menção ao "aprimoramento do educando como pessoa humana" e à sua "formação ética" e ao desenvolvimento do "pensamento crítico". Segundo Hansen (2005), são esses mesmos objetivos que orientam os muitos programas de leitura em escolas brasileiras:

O exame de alguns estudos sobre leitura escolar de ficção [...] poderia evidenciar que os programas atuais de ensino de literatura da escola pública são orientados crítica, estética e politicamente por noções católicas, liberais ou marxistas, que definem a finalidade da leitura de ficção pelos alunos da escola secundária como aprimoramento da sensibilidade, formação moral do caráter, conscientização de problemas sociais, reflexão, resistência, desautomatização do hábito, crítica da sociedade administrada, politização etc, herdadas dos séculos XVIII e XIX pelas vanguardas históricas e tematizadas até pelo menos os anos 1980 pela literatura modernista e moderna (HANSEN, 2005, p. 41).

Evidentemente, algumas dessas noções são belas e, se possíveis na escola brasileira contemporânea, trariam muitos ganhos. No entanto, a realidade de escolas lotadas, dos cursos noturnos, das péssimas condições materiais das salas de aula, da evasão do ensino médio (nível no qual a literatura é estudada de modo mais específico), da diminuição da carga horária de língua portuguesa, do baixo investimento em educação, tudo isso se impõe perversamente, de modo que o autor é levado a concluir sobre a falência desses ideais, tanto no Brasil quanto na França de onde tais modelos nos chegaram:

A desimportância e a desqualificação objetivas do seu valor-de-uso formador [da leitura literária], no velho sentido católico-burguês-liberal do século XIX, e do seu valor crítico, no sentido marxista, confirmam o que foi explicitado por Iser nos anos 1970, e o que Anne-Marie Chartier e Jean Hébrard demonstraram para a leitura literária da escola francesa: há muito a literatura não é mais o instrumento de formação, como foi na Europa do século XIX, quando a leitura dos clássicos da língua e da nacionalidade substituiu a teologia na educação adaptada à construção dos estados nacionais burgueses, função que ela teve por aqui [Brasil] até os anos 1960 (HANSEN, 2005, p. 43). 
O autor não deixa de marcar, ainda, que "no cotidiano das salas de aula essas belas noções estão arquivadas pelo movimento objetivo do capital, que produz a precariedade da escola pública, reproduzindo a exploração de classe" (HANSEN, 2005, p. 42). As reflexões de Hansen permitem olhar, portanto, as normativas governamentais sob outro prisma: o de sua relação com a realidade das escolas. Obviamente, seria muito alentador se pudéssemos atribuir à literatura e a seu ensino um lugar tão privilegiado no contexto escolar e, mais ainda, se as práticas efetivas de leitura dela feitas patrocinassem um leitor politizado, crítico, humano. Entretanto, por mais que a LDBEN no. 9.394/96 insista que o ensino médio pode ser terminal ou permitir o prosseguimento dos estudos, é preciso considerar que, para muitos, ele não é nem terminal e nem permite o prosseguimento de estudos, já que poucos conseguirão chegar ao ensino superior. ${ }^{2}$ Desse modo, sejam as diretrizes, os parâmetros ou as orientações governamentais, tais legislações parecem esbarrar em problemas maiores, que extrapolam o âmbito mais estrito dos limites dos conteúdos de literatura (o que ensinar, como ensinar, para que ensinar) que precisam ser pensados sob a ótica da realidade escolar, ou seja, é preciso repensar como fazer para que a literatura possa, de fato, cumprir seu papel na contemporaneidade.

Ao observar as orientações governamentais, com relação ao ensino da literatura, nota-se um descompasso entre os textos considerados ideais pelos documentos oficiais, o tipo de leitura que a escola procura ensinar e práticas de leitura ficcional reais que tem sido realizadas por jovens em idade escolar fora dos muros da escola (e dentro, ainda que de forma velada). Segundo Oliveira (2011), as aulas de literatura vistas na escola são aulas de História da Literatura e, desse modo, não se pode esperar um leitor crítico com tais moldes de ensino. Ainda segundo a autora, "a simples indicação de leitura de uma obra, seguida da avaliação dessa leitura realizada por meio de um trabalho ou de uma 'prova do livro', não garantem a leitura de um romance pelos alunos" (Oliveira, 2011, p. 360). Além dessas questões, a identificação dos alunos como não-leitores e a exclusão dos livros por eles efetivamente lidos das discussões em sala de aula certamente não ajudam os adolescentes em seu percurso de formação como leitores literários críticos.

Esse contexto aponta para o fato de que os letramentos sociais desses alunos não têm sido ressignificados e reconhecidos pela escola. Petermann e Dalla Vecchia (2014) discutem como o modelo autônomo de letramento está impregnado em campanhas de incentivo à leitura e mostram como o livro é legitimado como único portador textual de ficção. Segundo eles,

2 Em 2012, último ano em que o site do INEP apresentou números absolutos (frequência) dos alunos matriculados (8.376.852) e concluintes (1.877.960) do ensino médio, apenas $22,4 \%$ dos matriculados concluíam este nível de ensino. Para os anos de 2013 a 2016, o site não apresenta o número de concluintes. Entretanto, a julgar pelo próprio número de salas de primeira série (sempre muito superior) e de terceiras séries que observamos em escolas nas quais desenvolvemos projetos (PIBID, estágio curricular supervisionado), os percentuais não devem ser diferentes daquele de 2012. 
essas campanhas se embasam no modelo autônomo de letramento, pois consideram o domínio da escrita como essencial para 'ser mais', 'para obter status', evidenciando a marginalização daqueles que não estão inseridos nessa cultura. Além disso, é evidente a cultura escrita, representada pelo livro, como 'única via' humanizadora (DAlla Vechia e Petermann, 2014, s.p.).

Como se pode notar, particularmente em relação ao ensino de literatura, tanto os documentos governamentais quanto as práticas de leitura literária escolares, sobretudo no nível médio de ensino, estão permeados por uma concepção autônoma de letramento que hierarquiza textos e preconiza um só modelo de leitura. Alinhando-se à cultura letrada, tal modelo de leitura está diretamente associado à crítica e à historiografia literária; quanto à seleção de texto, pressupõe a leitura do cânone como ideal. Muito embora haja legitimidade nesse repertório e nesse modelo de leitura, cremos que eles não podem ser exclusivos, sob a pena de marginalizarem outros letramentos e outros textos, sobretudo na escola contemporânea, construída, indiscutivelmente, sob o símbolo da heterogeneidade. A partir dos subsídios dos estudos de letramento serão, a seguir, propostos os conceitos de "letramento ficcional" e de "letramento literário" que, cremos, podem subsidiar a compreensão do modo como tais letramentos ocorrem simultaneamente e independentemente da legislação educacional ou das imposições institucionais, sendo, portanto, práticas incontroláveis que, ao nosso ver, precisam ser discutidas e politizadas.

\section{Proposições conceituais de letramento literário e de letramento fic- cional}

Por aplicar-se a todos os usos da escrita, entre eles aos usos dos textos literários, o conceito de letramento se faz pertinente em relação à leitura de textos literários e de textos ficcionais em geral. Entretanto, ao considerar diferentes contextos e situações do uso da escrita, os estudos de letramento permitem focalizar diferentes formas de escrita e de leitura, sendo a leitura literária apenas uma delas. Dessa forma, cremos que o conceito de letramento se revela bastante pertinente para a compreensão das práticas de leitura realizadas tanto de textos literários (tanto em contexto escolar quanto fora dele) quanto de textos de natureza ficcional praticados no contexto atual, sobretudo por jovens e adolescentes, e que abarcam multimodalidades e mesmo de textos que não pertencem à cultura letrada ou à cultura dominante.

Para pensarmos nos conceitos de "letramento literário" e "letramento ficcional", como se propõe nesta seção, é preciso realizar uma pequena genealogia desses termos. Em 2008, em artigo intitulado "Modelos de letramento literário e ensino de literatura: problemas e perspectivas", Zappone utilizou-se das teorias de letramento propostas por Street (1994), sobretudo das concepções de modelo autônomo e ideológico, a fim de aplicar os conceitos de letramento aos estudos literá- 
rios, particularmente, à compreensão dos modos como a leitura de textos literários era (é) proposta pela escola. Sua compreensão era de que o termo "letramento literário" poderia abarcar tanto as práticas de leitura de textos literários quanto de outros textos ficcionais, de valorações culturais diferentes na cultura letrada e também os textos ficcionais produzidos em sistemas semióticos diferentes do verbal. Dessa forma, o conceito da autora, naquele momento, abrangia todas as práticas sociais de uso de textos ficcionais, independentemente de sua valoração cultural e da natureza semiótica de sua composição.

Antes, porém, em 2003, a coletânea de textos organizada por Paiva et al. e intitulada "Literatura e letramento: espaços, suportes e interfaces" apresentava alguns textos nos quais autores, entre eles Rangel (2007) e Zilberman (2007) tematizavam a questão tanto do "letramento literário" quanto da "leitura literária" (PAulino, 2005). Em 2006, Rildo Cosson publica o texto "Letramento literário: teoria e prática" no qual, da mesma forma que os autores da coletânea anterior, não faz menção a teorias de letramento, mas se apropria do termo, relacionando-o especificamente com as práticas de leitura escolares de textos literários. Desse modo, o sintagma "letramento literário" passou a circular socialmente, associado, especificamente, às práticas de uso de textos literários realizados no espaço escolar.

No caso da proposição desse artigo, o conceito de letramento se refere aos usos múltiplos e heterogêneos da escrita, demarcados por contextos sociais e objetivos também variados, portanto, trata-se de um conceito amplo que, ao ser adjetivado com o qualificativo "literário", sofre uma restrição apenas em relação ao tipo de escrita a que se está referindo. No caso do "letramento literário", portanto, o que se está conceituando são as práticas de uso de textos literários, ou seja, tanto a produção quanto a recepção de textos da tradição literária, ou seja, os usos dos textos valorizados na cultura letrada, já que o termo "literário" traz consigo as acepções de literatura previamente estabelecidas pela cultura letrada, relacionadas às escritas de valoração artística de natureza verbal.

Evidentemente, os usos dos textos literários são realizados mais frequentemente na escola, muito embora seja possível que seus usos sejam feitos também em situações não escolares, como por exemplo, uma secretária que lê Clarice Lispector no trabalho ou um biólogo que leia Eça de Queiroz ou mesmo um bancário que leia Lima Barreto. Como leem tais textos? Como se apropriam deles? Essas questões se relacionam diretamente ao que chamamos aqui de "letramento literário", ou seja, às práticas de uso efetivo, empíricos, de textos literários, mesmo que tais sujeitos não efetivem suas leituras a partir das práticas ensinadas/aprendidas na escola. Tendo em vista esse contexto acadêmico de utilização do termo "letramento literário", que considerava apenas os usos sociais de textos literários canônicos, e também observando que o adjetivo "literário" dizia respeito especificamente a textos literários, portanto, aos textos valorizados na tradição ocidental da cultura letrada, o grupo de pesquisa "Produção, recepção e circulação de textos", em suas discussões sobre o tema, entendeu ser melhor utilizar o sintagma "letramento literário" 
na mesma acepção com a qual ele já circulava academicamente, ou seja, como, exclusivamente, a práticas de uso de textos literários seja em contexto social ou em contexto escolar de textos literários valorizados pela cultura letrada. Assim, a acepção proposta por Zappone (2008), que reconhecia como "letramento literário" todos os usos de textos ficcionais, tornou-se pouco produtiva. Desse modo, o que se propõe é que o termo "letramento literário" seja conceituado, à luz do próprio conceito de letramento, como os usos de textos literários da cultura letrada (os textos canônicos), sejam tais usos feitos na escola ou fora dela. Para referir-nos aos usos de outros textos ficcionais, (aqueles que não recebem a mesma valoração dos textos canônicos), propomos o uso do termo "letramento ficcional", cujo conceito ficará mais claro a partir das explicações sobre os modelos de letramento a seguir.

O contexto social atual apresenta-se diversificado, fato causado pelas mudanças na comunicação, no desenvolvimento de tecnologias, na produção e circulação de informações e nos usos da língua (Rojo, 2009). Assim, por serem processos socioculturais, alteraram também as maneiras como se realizam as práticas de leitura e escrita em diferentes comunidades e espaços sociais. Dessa forma, é fundamental considerar a realidade do contexto social e a diversificação de práticas de letramento, pois os sujeitos assumem papéis múltiplos em diferentes esferas de atividade e transitam por contextos sociais onde produzem e partilham discursos e sentidos. O convívio social dos indivíduos em diferentes esferas proporciona a utilização da escrita em inúmeros contextos e para inúmeros objetivos, o que gera uma infinidade de práticas de letramento. Assim, pode-se afirmar que tais práticas, ditas no plural, são inúmeras, dependem e mudam a partir dos diferentes contextos em que a leitura e a escrita são realizadas, o que extrapola, evidentemente, os usos escolares. Esse fato é bastante significativo no caso dos textos ficcionais, pois os textos literários representam apenas uma parcela dos tipos de textos ficcionais acessados pelos indivíduos na vida social.

Nesse sentido, cremos que uma das principais contribuições dos estudos de letramento para os estudos sobre a leitura de textos literários é o fato de as teorias de letramento, sobretudo a compreensão dos modelos autônomo e ideológico, abrangerem as práticas de leitura de textos ficcionais realizadas para além do espaço escolar. Em relação a esse aspecto, o "letramento literário" parece ser mais frequentemente observado no espaço escolar, uma vez que a leitura de textos literários fora da escola é bem menos comum. Assim, vemos que as práticas de leitura do texto literário a que temos maior acesso e que possuem maior visibilidade são aquelas realizadas pela escola e que essas quase sempre se constroem segundo os padrões do modelo autônomo de letramento, pois consideram a autonomia do escrito como fonte suficiente para a produção de sentidos do texto.

No caso dos textos literários, o aspecto da autonomia torna-se ainda mais evidente do que em outros tipos de escrita, pois essa autonomia de sentido está relacionada a outros fatores não diretamente relacionados à construção do texto ou a seu modo de organização. Evidentemente, este aspecto também é extremamente 
pertinente, ou seja, contam na leitura do texto literário todos os elementos propriamente textuais, mas, além deles, são de importância capital os códigos relativos aos gêneros literários (da poesia, da epopeia, da narrativa de ficção, da crônica, do romance etc.), as convenções da escrita literária que são particulares de tempos e de espaços específicos (as convenções de escrita do romance brasileiro no séc. XIX, as convenções da escrita dramática na Inglaterra do séc. XVI, as convenções de escrita do modernismo, por exemplo, e inúmeras outras). Além dessas convenções, há outro elemento fundamental para a leitura do texto literário na escola que é a voz ou posição da crítica. Mesclando-se com os elementos já abordados, deve-se considerar que os sentidos do texto literário estão, muitas vezes, relacionados à compreensão dada a eles pela crítica ou pelas vozes da crítica. São essas vozes que organizam tanto as convenções quanto os códigos pertinentes aos textos, conduzindo a leitura do professor e do aluno por meio, inicialmente, da crítica e da historiografia, cujas ideias e valores reverberam no livro didático.

Assim, observa-se que a leitura de textos literários na escola alinha-se ao que Hansen (2005) denomina "leitura literária", ou seja, à leitura de textos considerados literários a partir de uma característica preponderante: seu caráter de ficcionalidade. Para esse autor, a leitura do texto literário parte da consideração de que ler literariamente implica, necessariamente, o reconhecimento do artifício de ficção criado no texto e, por isso, a condição sine qua non de tal leitura é que o leitor se posicione como o leitor imaginado pelo autor (leitor intratextual) a fim de produzir os sentidos adequados ao texto que são condicionados pelas convenções simbólicas a eles pertinentes:

Para que uma leitura se especifique como leitura literária, é consensual que o leitor deva ser capaz de ocupar a posição semiótica do destinatário do texto, refazendo os processos autorais de invenção que produzem o efeito de fingimento. Idealmente, o leitor deve coincidir com o destinatário para receber a informação de modo adequado. Essa coincidência é prescrita pelos modelos dos gêneros e pelos estilos, que funcionam como reguladores sociais da recepção, compondo destinatários específicos dotados de competências diversificadas; mas a coincidência é apenas teórica, quando observamos o intervalo temporal e semântico existente entre destinatário e leitor. Assim, a leitura literária é uma poética parcial ou uma produção assimétrica de sentido (HANSEN, 2005, p. 19-20).

Aguiar (200o) também defende posição semelhante, ao afirmar que a leitura literária, notadamente aquela realizada pelos críticos literários, tem como princípio a observação do decoro particular dos textos literários, ou seja, a leitura literária tem como condição básica o conhecimento das normativas que regem o modo particular de construção dos textos literários. Assim, ler literariamente implica conhecer tais normas de composição e interpretá-las:

A leitura literária é uma experiência do imaginário figurado nos textos feita em liberdade condicional. Para fazê-la, o leitor deve refazer - e in- 
sisto no 'deve' - as convenções simbólicas do texto, entendendo-as como procedimentos técnicos de um ato de fingir (HANSEN, 2005, p. 26).

Toda obra de arte impõe um decoro particular. No nível mais simples, diríamos: de personagens cômicos, esperamos gestos cômicos; de trágicos, trágicos; e assim por diante. Mas há questões mais complexas. Ao lermos um romance, veremos seres - (...) - os personagens - muito parecidos conosco, as pessoas, digamos, reais. Mas eles não são nós. Não agem, no fundo, como nós. Pode-se dizer que são melhores do que nós. Não padecem da incoerência do nosso cotidiano. (...) Na arte, o vilão mais vilão será sempre mais virtuoso do que o mais virtuoso santo na vida real. Há um comportamento, portanto, que é próprio desse mundo, e que só a ele pertence. A esse conjunto de expectativas geradas e de gestos que com elas estejam de acordo, chamamos decoro. Um conceito fundamental para entender o valor de uma obra literária, até porque hoje muitos efeitos surpreendentes derivam de quebras pertinentes do decoro, que geram ironias e despertam a reflexão (AgUiAR, 2000, p. 20-21).

Como se nota, a característica de autonomia na leitura do texto literário se constitui no padrão segundo o qual as práticas de letramento escolar se constroem na escola, ou seja, um padrão constituído a partir da consideração do que é ler literariamente. Assim, a leitura literária esperada pela agência escolar se refere a uma habilidade de leitura muito específica e altamente especializada, pois é uma leitura que pressupõe alto grau de preparo de seu leitor e de alinhamento aos preceitos da teoria literária, da crítica e também da historiografia.

Entretanto, se considerarmos que o "letramento ficcional" diz respeito às práticas de uso de textos ficcionais (entre os quais figuram os literários) em contextos diversos e para objetivos também diversos, a leitura literária produzida na escola torna-se apenas uma entre as tantas práticas possíveis de usos dos textos literários na sociedade. Assim, é preciso considerar como "letramento literário" as práticas de leitura de textos literários (textos valorizados pela cultura letrada) mesmo quando tais práticas não seguem o padrão autônomo (leitura literária) estabelecido pela agência escolar. Assim, constituem "letramento literário" as apropriações que usuários das redes sociais fazem, por exemplo, dos textos de Clarice Lispector ou Caio Fernando Abreu ou Carlos Drummond ao usá-las como aforismos no Facebook ou Instagram. Ou mesmo as leituras desconhecidas que leitores anônimos podem fazer desses autores e de tantos outros fora da escola que podem não levar em conta as particularidades do discurso literário consideradas pela crítica especializada como relevantes para a leitura da literatura. Desse modo, o que queremos mostrar é que o "letramento literário", ou seja, as práticas de uso da literatura são variadas na vida em sociedade, e que o "letramento literário" escolar - aquele que pressupõe o conhecimento das particularidades do discurso literário e que foi descrita nesses textos como leitura literária - é apenas um dentre tantos usos que os indivíduos podem fazer da literatura. 
Além de considerar os possíveis usos da literatura na vida social, ou seja, as diversas práticas de letramento em torno do literário, as discussões sobre letramento também instigaram a refletir sobre os impactos das novas tecnologias nos letramentos. Como lembra Jay Lemke, o letramento nunca implicou o uso exclusivo do impresso ou do escrito, tal como nossa sociedade logocêntrica nos faz acreditar: "Faz um bom tempo que as tecnologias do letramento não são tão simples quanto a caneta, a tinta e o papel. E na era da imprensa, assim como antes dela, o letramento raramente esteve atrelado de forma estrita ao texto escrito" (LEMKE, 2010, p. 1). Além de Lemke, outro autor que discute novas tecnologias é Henry Jenkins (2006), para quem as textualidades não verbais sempre circularam, chegando o autor a citar o caso da história de Cristo, por ele considerada uma narrativa transmídia:

Veja, por exemplo, a história de Jesus, conforme contada na Idade Média. Ao menos que se soubesse ler, Jesus não era fundamentado em livros, mas algo que se encontrava em múltiplos níveis de cultura. Cada representação (um vitral, uma tapeçaria, um salmo, um sermão, uma apresentação teatral) presumia que o personagem e sua história já eram conhecidos de algum outro lugar (JENKINS, 2006, p. 172).

Com o advento de novas tecnologias, cada vez mais os modos de produção de significado na contemporaneidade têm se expandido do suporte "papel" para outras mídias, de modo que novas formas de produção de significados, em diferentes sistemas semióticos (combinados ou não) têm se tornado possíveis. Dentre elas, podem-se citar algumas "textualidades eletrônicas" (Aranha, 2008), construídas a partir do princípio de "remediação", ou seja, do "processo através do qual um meio se apropria de outros que o antecederam, adaptando-os às demandas de transferência de experiências sensoriais entre dois ou mais agentes em seu contexto socioeconômico cultural" (ARANHA, 2008, p. 40-41). Ou seja, trata-se de uma remodelação de um meio ou de um sistema semiótico para outro(s) sempre impulsionada por novas exigências culturais, históricas, sociais e tecnológicas. Tal processo pode ser observado, por exemplo, na passagem das narrativas ficcionais, antes apresentadas em forma escrita (romances, contos, em folhetins etc.) e que, atualmente, são "remediadas" para formas cinematográficas ou televisivas. Outro exemplo de remediação pode ser visto nos mangás (formas mistas de verbal impresso e imagem) que foram/são remediadas para os animes (formas verbais orais, imagem e movimento). Atualmente, as narrativas ficcionais passam por outros processos de remediação, não só ao agregarem diferentes sistemas semióticos, mas também por permitirem uma participação mais efetiva dos públicos, como se nota, por exemplo, nos jogos eletrônicos, que objetivam produzir a sensação de experiência viva por parte dos leitores-receptores.

Como afirma Lemke (2010), diante desse quadro no qual o modo verbal e impresso passa a conviver intensamente com outras modalidades (diferentes sistemas semióticos), os letramentos expandem-se e exigem dos indivíduos o desenvolvimento de práticas multimidiáticas de leitura e escrita: "habilidades de autoria 
multimidiática e análise multimidiática correspondem de forma aproximada a habilidades tradicionais de produção textual e de leitura crítica" (LEMKE, 2010, p. 5).

Ao considerarmos as textualidades contemporâneas que possuem caráter de ficcionalidade, podemos falar de "letramento ficcional" para nos referirmos às práticas de uso de textos ficcionais (seja produção ou leitura) dos sujeitos (sobretudo jovens e adolescentes) que acessam frequentemente formas narrativas que se valem do verbal, das imagens, dos movimentos, sons, associando diferentes modalidades ou sistemas semióticos. Nesse caso, o termo "letramento ficcional" se mostra abrangente, pois abarca tanto o uso de formas ficcionais verbais quanto multimodais.

Tendo em vista tais práticas, podemos conceituar, portanto, o "letramento ficcional" como os usos sociais da escrita ficcional, aquela constituída tanto a partir dos sistemas verbais tradicionais veiculados pelo impresso (nos quais se inclui a literatura canônica) quanto as formas que associam outros sistemas semióticos, nos mais diversos contextos e com os diversos objetivos que possam ter. Não se pode esquecer que tais formas ficcionais, evidentemente, abarcam desde os textos tradicionais (a literatura canônica) até formas narrativas menos valorizadas, tais como as narrativas da indústria cultural (o best-seller, o mangá, o anime, as séries televisivas, os vídeos das redes sociais, os jogos eletrônicos, o cinema) que gozam, evidentemente, de prestígio diferenciado dentro da cultura letrada.

Embora ocupem diferentes lugares de valoração na sociedade, o que se observa é que elas constituem práticas de "letramento ficcional" bastante realizadas, sobretudo entre leitores jovens. Nesse sentido, o "letramento ficcional" compreende tanto a produção/leitura de textos ficcionais que os jovens realizam na escola (normalmente, os textos da tradição), quanto de outros textos ficcionais cujas práticas cotidianas situam-se fora do ambiente escolar. O conceito de "letramento ficcional" (no qual se inclui o "letramento literário" aqui proposto) não se refere apenas à produção/recepção da literatura em obras consagradas, consideradas relevantes, tampouco a partir de um conhecimento literário específico, mas às formas de construir sentidos e valores das diversas formas nas quais histórias ou textos ficcionais de vários gêneros, de várias culturas e em diferentes modalidades, são produzidos e lidos no mundo contemporâneo.

Ao considerar a existência de todas essas práticas de "letramento ficcional", produz-se uma politização das mesmas, uma vez que deixam de existir enquanto práticas marginais e passam a ser consideradas como práticas legítimas, ou seja, que têm uma existência real, mesmo que paralelamente a outras práticas mais valorizadas (normalmente, as escolares).

Enfim, para abarcar todas as práticas que envolvem a leitura e a escrita de formas ficcionais, cremos ser pertinente o uso do termo "letramento ficcional", visto que ele abrange tanto os usos de textos literários canônicos, em âmbito escolar e não escolar, quanto os usos sociais de textos ficcionais não canônicos e, para além 
deles, a produção/recepção de formas ficcionais multimodais ou multissemióticas. A partir dos estudos de letramento, propomos, portanto, que as práticas de uso de textos ficcionais, nas quais se incluem as práticas de uso dos textos literários canônicos, seja compreendida como "letramento ficcional".

Sabendo que tanto os textos literários selecionados para leitura nos espaços acadêmicos e escolares quanto a leitura para eles propostas são mais visíveis e valorizados, é pertinente que tais letramentos possam ser particularizados, de modo que tais práticas, mesmo sendo também formas de "letramento ficcional", possam receber nomenclatura própria. Sendo assim, tendo em vista que o termo "letramento literário" já se sedimentou junto a pesquisadores da área de literatura, tal como se notou em Rangel (2007), Zilberman (2007), Paulino (2008) e Cosson (2006), na acepção de usos da literatura canônica, propomos que seja essa a forma de nomearmos todas as práticas de uso dos textos literários, sejam elas realizadas nos espaços acadêmico e escolar, sejam realizadas fora da escola a partir de situações/contextos e objetivos particulares de leitores plurais.

\section{Considerações finais}

Se a leitura constitui, como defende De Certeau, e com o qual concordamos, uma prática plural, variável no tempo-espaço, e que é alvo de controle e censura social das mais diversas maneiras (seja pela hierarquização de textos, seja pela valorização ou desvalorização de modos de ler que tendem, por sua vez, a hierarquizar leitores menos e mais competentes, menos e mais autorizados), a proposta desse texto foi a de pensarmos os usos da escrita, nos quais se incluem todas as formas de leitura, a partir dos estudos de letramento.

Na perspectiva teórica de letramento apresentada, entende-se que os usos da escrita (no qual se inclui a leitura) são plurais, contextuais, dependentes das relações estabelecidas entre os interlocutores, que são sempre, relações de poder. Logo, não há letramento ou leitura que se faça fora do jogo político, pois também nas práticas de leitura atuam as forças da divisão do trabalho que estabelecem quais sujeitos/lugares sociais determinam as "regras do jogo". Os estudos de letramento, destituindo-se de olhar judicativo sobre os diversos usos da escrita, propõem a descrição e a compreensão das práticas de usos da escrita, entre as quais se pode, como aqui fizemos, incluir a leitura da literatura. Sobre essa, como vimos, as leituras e textos escolares parecem ser as mais conhecidas e valorizadas. No entanto, ao olharmos a realidade, podemos observar inúmeras outras práticas de uso de textos ficcionais que abarcam tanto os textos literários canônicos (lidos na escola e fora dela, ainda que de modo rarefeito) quanto de textos de ficcionais de outras esferas e culturas e de natureza multimodal, tais como séries televisivas, cinema, videogames, óperas, novelas, mangás, animes, histórias em quadrinhos e outros. Todos eles constituem letramentos e, tal como De Certeau (2003, p. 268), cremos que "uma política da leitura deve, portanto, articular-se a partir de uma análise que, descrevendo práticas há muito tempo efetivas, as torne politizáveis”. Longe 
de propor hierarquizações sobre textos ou modos de ler, as proposições terminológicas de "letramento literário" e "letramento ficcional" apresentadas nesse texto objetivaram discutir e, portanto, politizar práticas de leitura de textos ficcionais no contexto contemporâneo, de modo a contribuir para que as discussões sobre tais leituras, sobretudo aquelas feitas sob a ótica escolar (que oscilam entre certo e errado, próprio e impróprio) possam levar em conta os espaços, tempos, os comos e os porquês da leitura, situando-a como uma prática plural. Assim, as leituras que passam ao largo do espaço escolar deixam de ser invisíveis, para que leitor algum e leitura alguma necessitem ser vistos como transgressores, sub-reptícios ou inadequados frente às experiências letradas de leitura que, ainda que sejam as mais complexas, nunca serão únicas e, talvez, nem mesmo as mais críticas.

\section{Referências}

Aguiar, Flávio. As questões da crítica literária. In: Martins, Maria Helena et al. Outras leituras: literatura, televisão, jornalismo de arte e cultura, linguagens interagentes. São Paulo: Itaú Cultural, 2000. p. 19-36.

Aranha, Gláucio. Narratologia e jogos eletrônicos. In: Oswald, Maria Luiza M Bastos; Pereira, Rita Maria Ribes (orgs). Infância e juventude: narrativas contemporâneas. Petrópolis: DP; Rio de Janeiro: Faperf, 2008. p. 31-47.

Barton, David; Hamilton, Mary; Ivanic, Roz (orgs.). Situated literacies: reading and writing in context. Londres e Nova York: Routledge, 2000.

Barton, David; Hamilton, Mary; Ivanic, Roz (orgs.). La literacidad entendida como práctica social. In: Zavala, Virgínia; Niño-Murcia; Mercedes; Ames, Patricia (orgs.). Escritura y sociedade: nuevas perspectivas teóricas y etnográficas. Lima/Peru: Rede para el Desarrollo de las Ciencias Sociales em el Peru, 2004.

Brasil. Lei de Diretrizes e Bases da Educação Nacional. Lei número 9394, 20 de dezembro de 1996.

Brasil. Ministério da Educação, Secretaria de Educação Média e Tecnológica. Parâmetros Curriculares Nacionais: ensino médio. Brasília: Ministério da Educação, 1999.

BRAsIl. Ministério da Educação, Secretaria de Educação Básica. Orientações curriculares nacionais para o ensino médio. Brasília: Ministério da Educação, 2006.

Cosson, Rildo. Letramento literário: teoria e prática. São Paulo: Contexto, 2006.

Dalla Vechia, Adriana; Petermann, Rafael. Campanhas Nacionais de incentivo à leitura no Brasil: uma análise sob o olhar dos novos estudos do letramento. In: Encontro Sul Letras, 3, out. 2014. Santa Cruz, Paraná. Anais... Santa Cruz, Paraná: Sulletras/Unicentro, 2014, p. 613-626. Disponível em: https://anais.unicentro. br/sulletras/pdf/iiivını/completos/iii_sulletras_unicentro.pdf. Acesso em: 19 mar. 2015 . 
De Certeau, Michel. Ler: uma operação de caça. In: De Certeau, Michel. A invenção do cotidiano: artes de fazer. São Paulo: Vozes, 2003. p. 259-270.

GEE, James. Paul. Social linguistics and literacies: ideology in discourses. Londres: The Falmer Press, 1990.

Hansen, João Adolfo. Reorientações no campo da leitura literária. In: Abreu, Marcia; Schapoснniк, Nelson (orgs.). Cultura letrada no Brasil: objetos e práticas. Campinas: Mercado de Letras, 2005 .

Jenkins, Henry. Em busca do unicórnio de origami: Matrix e a narrativa transmídia. In: Jenkins, Henry. Cultura da convergência. São Paulo: Aleph, 2009. p.135-186.

Jung, Neiva. Maria. Identidades sociais na escola: gênero, etnicidade, língua e as práticas de letramento em uma comunidade rural multilíngue. 2003. Tese (Doutorado em Letras) - Instituto de Letras, Universidade Federal do Rio Grande do Sul, Porto Alegre, 2003. Disponível em: https://lume.ufrgs.br/handle/10183/115757. Acesso em: 19 mar. 2012.

Kato, Mary. No mundo da escrita: uma perspectiva psicolinguística. São Paulo: Ática, 1986.

Kleiman, Angela. Modelos de letramento e as práticas de alfabetização na escola. In: Kleiman, Angela (org.). Os significados do letramento: uma nova perspectiva sobre a prática social da escrita. Campinas: Mercado de Letras, 1995.

LEMKE, Jay L. Letramento metamidiático: transformando significados e mídias. Trabalhos em linguística aplicada, Campinas, v. 49, n. 2, p. 455-479, jul/dez. 2010. Disponível em: https://www.scielo.br/scielo.php?script=sci_arttext\&pid=So10318132010000200009\&lng=pt\&nrm=iso. Acesso em: 19 mar. 2012.

Oliveira, Gabriela Rodella. Sobre as práticas de leitura literária de alunos do ensino médio. Anais da SIELP, Uberlândia, v. 1, n. 1. p. 358-367, 2011. [on-line]. Disponível em: http://www.ileel.ufu.br/anaisdosielp/wp-content/uploads/2014/ o6/volume_1_artigo_o4o.pdf. Acesso em: 19 mar. 2012.

Paulino, Maria das Graças Rodrigues. Algumas especificidades da leitura literária. In: PAIVA, Aparecida et al. Leituras literárias: discursos transitivos. Belo Horizonte: Autêntica, 2008. p. 56-68.

RANGEL, Egon de Oliveira. Letramento literário e livro didático de língua portuguesa: os amores difíceis. In: PAIvA, Angela et al. Literatura e letramento: espaço, suportes e interfaces. Belo Horizonte: Autêntica, 2003. p. 127-146.

Rojo, Roxane. Letramento (s) - práticas de letramento em diferentes contextos. In: Rojo, Roxane. Letramentos múltiplos, escola e inclusão social. São Paulo: Parábola Editorial, 2009. p. 95-129.

SoARes, Magda. Letramento: um tema em três gêneros. Belo Horizonte: Autêntica, 2003. 
Street, Brian V. Literacy in theory and practice. Cambridge: Cambridge University Press, 1984.

Street, B. Literacy in theory and practice. Austrália: University of Cambridge, 1999.

StREeT, Brian V. Literacy and Development: ethnographic perspectives (org.). London: Routledge, 2001.

Street, Brian V. What's "new"in New Literacy Studies? Critical approaches to literacy in theory and practice. Current Issues in Comparative Education, Teachers College, Columbia University, Vol. 5(2), 2003a.

Street, Brian V. Abordagens alternativas ao letramento e desenvolvimento. Teleconferência Unesco Brasil sobre Letramento e Diversidade. out. 2003b.

Street, Brian V. Letramentos sociais: abordagens críticas do letramento no desenvolvimento, na etnografia e na educação. São Paulo: Parábola, 2014.

Tfouni, Leda Verdiani. Adultos não alfabetizados: o avesso do avesso. Campinas: Pontes, 1988.

Tfouni, Leda Verdiani. Letramento e alfabetização. São Paulo: Cortez, 1995.

Zappone, Mirian Hisae Yaegashi. Modelos de letramento literário e ensino da literatura: problemas e perspectivas. Teoria e Prática da Educação, v. 11, n. 1, p.496o, jan./abr. 2008. Disponível em: https://social.stoa.usp.br/articles/oo37/3065/ Modelos_de_Letramento_Liter_rio.pdf. Acesso em: 19 mar. 2012.

ZilBerman, Regina. Letramento literário: não ao texto sim ao livro. leituras. In: PAIva, Angela et al. Literatura e letramento: espaço, suportes e interfaces. Belo Horizonte: Autêntica, 2003. p. 245-266.

Recebido em 21 de janeiro de 2020.

Aprovado em $1^{\circ}$ de março de 2020 .

\section{Resumo/Abstract/Resumen}

Letramento ficcional e letramento literário: reflexões sobre usos de textos ficcionais a partir dos estudos de letramento

\section{Mirian Hisae Yaegashi Zappone}

\section{Stéfanny Barranco do Nascimento}

A contemporaneidade abre espaço para a prática de variados eventos de letramento. Esses espaços estão repletos de mídias que permitem conexão ininterrupta, potencializando uma comunicação mais fluida e híbrida. Nesse sentido, as relações com o livro e com a literatura acabam sofrendo modificações. Sabe-se que a 
cultura de massa influencia a formação do gosto dos leitores, e que a escola tem um papel importante nessa formação. Tendo em vista essa pluralidade nos processos de produção e recepção de textos ficcionais, partindo da perspectiva dos Novos Estudos de Letramento, esse artigo tem objetivo de realizar uma revisão teórica sobre letramento e, a partir dela, propor o conceito de "letramento ficcional" e de refinar o conceito de "letramento literário". Para tanto, retomamos os conceitos de letramento, de "letramento literário" e os associamos a reflexões sobre o modo como a escola lida com textos ficcionais, particularmente, sobre o modo de ler ideal de leitura do texto literário proposto pelas diretrizes governamentais e sobre o modo como os textos ficcionais são utilizados na vida social.

Palavras-chave: letramento, textos ficcionais, escola.

Fictional and literary literacy: discussion on the use of fictional texts as from literacy studies

\section{Mirian Hisae Yaegashi Zappone}

\section{Stéfanny Barranco do Nascimento}

Contemporaneity creates spaces for the holding of various literacy events. These spaces, full of media with uninterrupted connections, are capable of maintaining a more fluid and hybrid communication. In this sense, the relationship with books and literature undergo changes. It is a well-known fact that mass culture affects the development of readers' tastes and that the school plays an important role in this. Due to the plurality of production and reception processes in fictional texts from the perspective of New Literacy Studies, this paper comprises a theoretical review of literacy and proposes the concept of fictional literacy. The concept of literary literacy and its specificities will be discussed. It will be associated to discussions on the manner the school deals with fictional texts, especially the ideal manner of reading literary texts, as proposed by government guidelines and the way fictional texts are used in social life.

Keywords: literacy, fictional texts, school.

Lectoescritura ficcional y lectoescritura literaria: reflexiones sobre el uso de textos ficcionales a partir de los estudios de lectoescritura

\section{Mirian Hisae Yaegashi Zappone \\ Stéfanny Barranco do Nascimento}

La contemporaneidad abre un espacio para la práctica de variados eventos de lectoescritura. Estos espacios están repletos de medios de comunicación que permiten una conexión continua, potenciando una comunicación fluida e híbrida. En este sentido, las relaciones con el libro y con la literatura llegan a sufrir alteraciones. Se sabe que la cultura de masas influye sobre la formación del gusto de los lec- 
tores, y que la escuela desempeña un papel importante en esa formación. Considerando esta pluralidad en los procesos de producción y recepción de los textos ficcionales, a partir de la perspectiva de los Nuevos Estudios de Lectoescritura, este artículo tiene como objetivo realizar una revisión teórica sobre la lectoescritura y, a partir de ella, proponer el concepto de "lectoescritura ficcional" y refinar el concepto de "lectoescritura literaria". Para ello, nos servimos de los conceptos de lectoescritura y"lectoescritura literaria", asociándolos a reflexiones sobre el modo en qual la escuela trabaja con los textos ficcionales, especialmente sobre el modo ideal de lectura del texto literario propuesto por las directrices gubernamentales, bien como sobre el modo en que los textos ficcionales son utilizados en la vida social.

Palabras clave: lectoescritura, textos ficcionales, escuela. 